\title{
Endovascular Treatment of a Giant Dissecting Aneurysm in an Infant
}

\section{Tratamento endovascular de aneurisma dissecante gigante em um bebê}

\author{
Luana Antunes Maranha Gatto ${ }^{1}$ Adriel Barro ${ }^{2}$ Rafaella do Rosario Tacla ${ }^{2}$ Zeferino Demartini jr ${ }^{1}$ \\ Gelson Luis Koppe ${ }^{3}$ \\ ${ }^{1}$ Department of Neurosurgery and Interventional Neuroradiology, \\ Hospital Universitário Cajuru da Pontifícia Universidade Católica \\ (HUC-PUC), Curitiba, PR, Brazil \\ ${ }^{2}$ Academic of Medicine, Hospital Universitário Cajuru da Pontifícia \\ Universidade Católica (HUC-PUC), Curitiba, PR, Brazil

\begin{abstract}
Address for correspondence Luana Antunes Maranha Gatto, Master, Departamento de Neurocirurgia e Neurorradiologia Intervencionista, Hospital Universitário Cajuru da Pontifícia Universidade Católica (HUC-PUC), Av. São José, 300. Cristo Rei, 80050-350, Curitiba, PR,
\end{abstract} \\ Brazil (e-mail: luanamaranha@yahoo.com.br).
}

${ }^{3}$ Department of Interventional Neuroradiology, Hospital Universitário Cajuru da Pontifícia Universidade Católica (HUC-PUC), Curitiba, PR, Brazil

Arq Bras Neurocir 2018;37:217-222.

Abstract
Keywords
- intracranial
aneurysms
- dissecting aneurysm
- therapeutic
embolization
- carotid artery
diseases
- endovascular
procedure
- child

\section{Resumo}

Introduction The incidence of intracranial aneurysms in the pediatric population is low, and endovascular treatment is becoming a safe and minimally invasive treatment option. In the present study, the occurrence of special features of cerebral aneurysm in children, in comparison to adults, is also described.

Case Report A 3-month-old female infant presented with progressive proptosis and divergent strabismus at the right eye, in addition to inconsolable crying. Cerebral resonance, angiotomography and angiography exams demonstrated angiodysplasia in the right internal carotid artery with two large paraclinoid dissecting aneurysms with wide neck. The right internal carotid artery was occluded with coils by endovascular approach, without detriment to the perfusion of the ipsilateral hemisphere and without neurological deficits. The patient achieved good recovery, and a late control angiotomography confirmed the exclusion of the aneurysms.

Conclusion Parent artery sacrifice via endovascular approach is an effective therapeutic option, but a long-term follow-up is necessary to avoid recurrence and bleeding.

Introdução A incidência de aneurismas intracranianos na população pediátrica é baixa e o tratamento endovascular está se tornando uma opção de tratamento seguro e received

January 27, 2018

accepted

June 8, 2018

published online

August 20, 2018
DOI https://doi.org/

10.1055/s-0038-1668495. ISSN 0103-5355.
Copyright $(2018$ by Thieme Revinter

Publicações Ltda, Rio de Janeiro, Brazil
License terms

(c) (i) $\ominus$ (\$) 


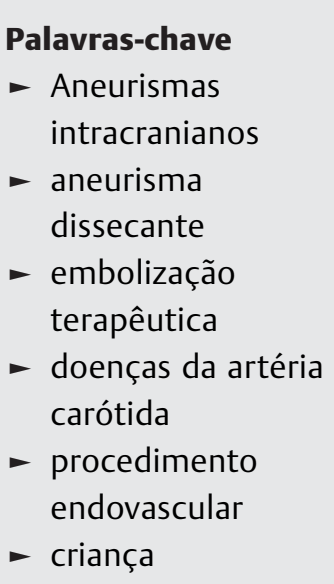

minimamente invasivo. No presente estudo, são descritas as características especiais de aneurismas cerebrais em crianças, em comparação aos adultos.

Relato do Caso Uma criança de 3 meses de idade, do sexo feminino, apresentou proptose progressiva e estrabismo divergente no olho direito, além de choro inconsolável. Ressonância cerebral, angiotomografia e arteriografia demonstraram angiodisplasia na artéria carótida interna direita com dois grandes aneurismas paraclinoides dissecantes com colo largo. A artéria carótida interna direita foi ocluída com coils por via endovascular, sem prejuízo da perfusão do hemisfério ipsilateral e sem déficits neurológicos. A paciente obteve boa recuperação e uma angiotomografia de controle tardia confirmou a exclusão dos aneurismas.

Conclusão O sacrifício da artéria parental por via endovascular é uma opção terapêutica efetiva, mas um acompanhamento em longo prazo é necessário para evitar recidiva e sangramento.

\section{Introduction}

Cerebral aneurysms in childhood are rare, representing less than $5 \%$ of all aneurysms treated in large centers ${ }^{1}$ (ranging from $0.95-6.8 \%$ of the population with this condition). ${ }^{2}$ As little as $\sim 1,200$ cases were reported between 1939 and 2011 , and 131 cases from before 1966 until 2005. ${ }^{2}$ The incidence is very rare before 15 years of age, representing $1 \%$ of all aneurysms. ${ }^{3}$ Unlike the adult population, there is a male predominance, with a male-to-female ratio of $\sim 3: 2 .{ }^{4}$

The morphology, clinical presentation, and radiological features of aneurysms in infants and children are different from those of aneurysms in adults. ${ }^{5}$ They also differ due to the lack of exposure to environmental factors and comorbidities commonly found in adults (for example, smoking, arterial hypertension and excessive chronic alcohol intake), but children with preexisting diseases may be predisposed to the formation of these aneurysms. ${ }^{2}$

The location of the aneurysms also differs in children, with the internal carotid artery (ICA) being the most common site, accounting for 13 to $50 \%$ of the incidence, while posterior circulation aneurysms are also more frequent in children than in adults. ${ }^{3}$ However, giant aneurysms $(\geq 25 \mathrm{~mm})$ in infants, on the contrary, arise more frequently in the posterior circulation. ${ }^{5}$

Treatment options for pediatric ICA aneurysms include conservative management, direct surgical clipping, cerebral revascularization and an endovascular approach. ${ }^{3}$ There is no consensus for the management of pediatric aneurysms and its approach remains individualized on a case-by-case basis. ${ }^{5}$

In the present study, we report the case of an infant with a giant, partially thrombosed, carotid-ophthalmic aneurysm, which was treated with parent vessel occlusion by endovascular approach, and present a discussion about the epidemiology, etiology, location and treatment options for aneurysms in the pediatric population.

\section{Case Report}

A 3-month-old female infant presented since her 1st month of life with recurrent episodes of inconsolable crying, especially during breastfeeding. On clinical examination, it was also noted a discreet proptosis and divergent strabismus in the right eye ( - Fig. 1). Anthropometric data, strength, tonus and reflexes were unremarkable. Computed tomography (CT) and

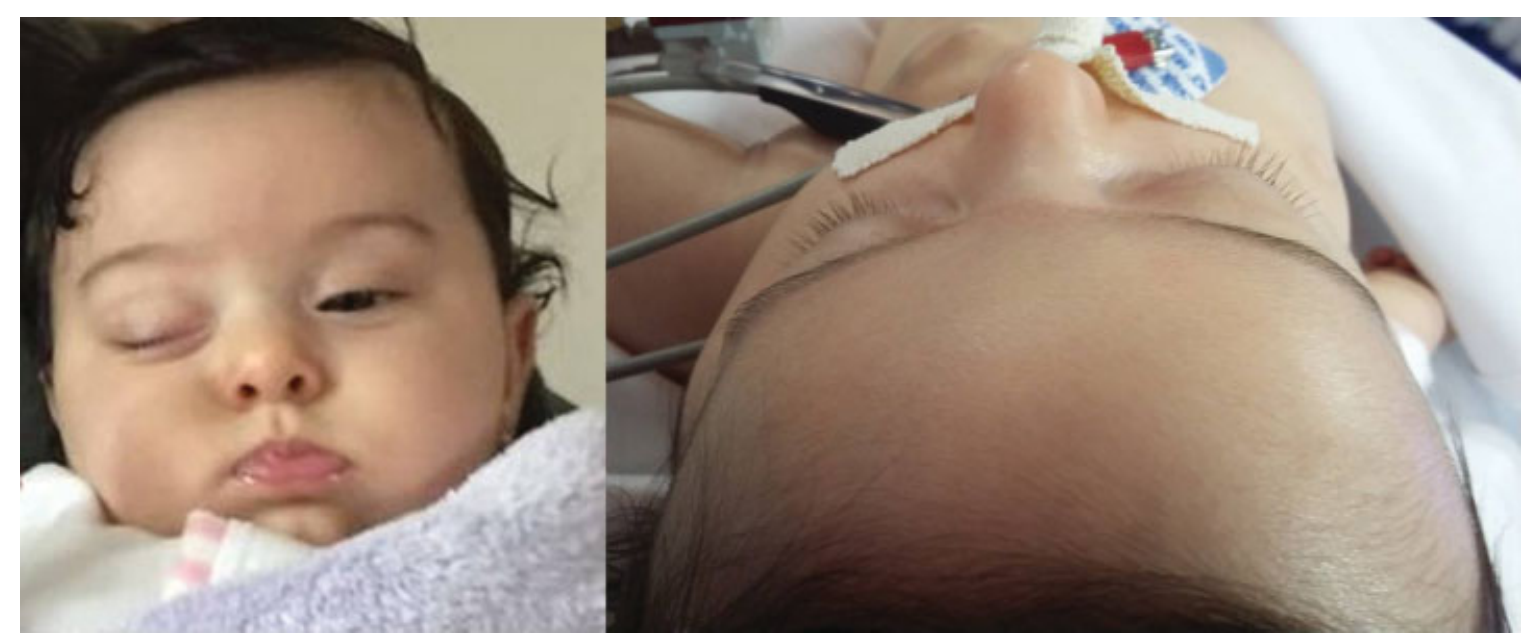

Fig. 1 Proptosis and ptosis on the right eye before the procedure. Image usage authorized by signed and acknowledge Informed Consent. 
magnetic resonance imaging (MRI) exams of the brain showed a large retro-orbital mass with $29 \mathrm{~mm}$ in the largest diameter, producing local mass effect. As it was not possible to differentiate between a vascular or neoplastic etiology of the mass, a CT angiography (CTA) was requested (-Fig. 2 ). The CTA confirmed the presence of a partially thrombosed aneurysm in the ophthalmic segment of the right ICA (-Fig. 3). A digital subtraction angiography (DSA) of the intracranial vessels revealed 2 dissecting aneurysms, in tandem, in the right ICA: one in the supraclinoid region measuring $5 \mathrm{~mm}$ in the largest diameter, and the other in the ophthalmic segment, measuring $17 \mathrm{~mm}$, both with a wide neck. In addition, the ICA itself had a dysplastic aspect from its origin, with diffuse tapering and a morphological aspect of malformation (-Fig. 4). The Matas test was performed, which detected no damage to the right hemisphere perfusion (-Fig. 5). Given the high risk of microsurgery at this age and the postprocedure increase in local mass effect by embolization, we opted for the occlusion of the right ICA with platinum coils. The final angiographic control demonstrated significant contrast stagnation in the topography of the aneurysms, as well as patency of the ipsilateral parenchymal filling through the Willis polygon (-Fig. 6). The episodes of inconsolable crying ceased completely 3 days after the procedure. The infant was followed-up in the outpatient clinic for 5 months. There were no neurological repercussions during the follow-up. A control CTA exam performed 12 months after the procedure demonstrated complete aneurysm thrombosis and a regression of $\sim$ $90 \%$ of the volume on the largest aneurysm. A minor proptosis and a discrete strabismus persisted, probably due to the mass effect of the thrombosed aneurysms, which should improve gradually with their absorption (-Fig. 7).

\section{Discussion}

Although the most common aneurysm site in children is the ICA, in particular at its terminal ending, ${ }^{5}$ case reports of infants with giant aneurysms in the anterior circulation as the one reported here are extremely rare. ${ }^{5}$ Dissecting and fusiform aneurysms are relatively common in children in contrast to adults, who typically present saccular aneurysms (45\% in the series of Lasjaunias). ${ }^{4}$ Non-traumatic dissecting aneurysms in the pediatric population are most commonly found at the level of the supraclinoid ICA, in the middle cerebral artery, and in the posterior circulation. ${ }^{4}$ The thrombosed components in giant aneurysms seen on imaging studies are not intraluminal but are likely to be intramural hematomas similar to those seen on large arterial dissections. ${ }^{5}$

In most cases, the etiology of infant intracranial aneurysms remains unknown. ${ }^{5}$ This is consistent with our patient, as the infant presented with an aneurysm that could not have risen from inflammatory, traumatic or infective causes. Underlying comorbidities are found in up to one third of the children with intracranial aneurysms, such as reticular fiber deficiency, gene mutations interfering with the extracellular matrix, and connective tissue diseases, including Marfan syndrome, coarctation of the aorta, Ehler-Danlos syndrome type IV, and fibromuscular dysplasia, besides polycystic kidney disease,

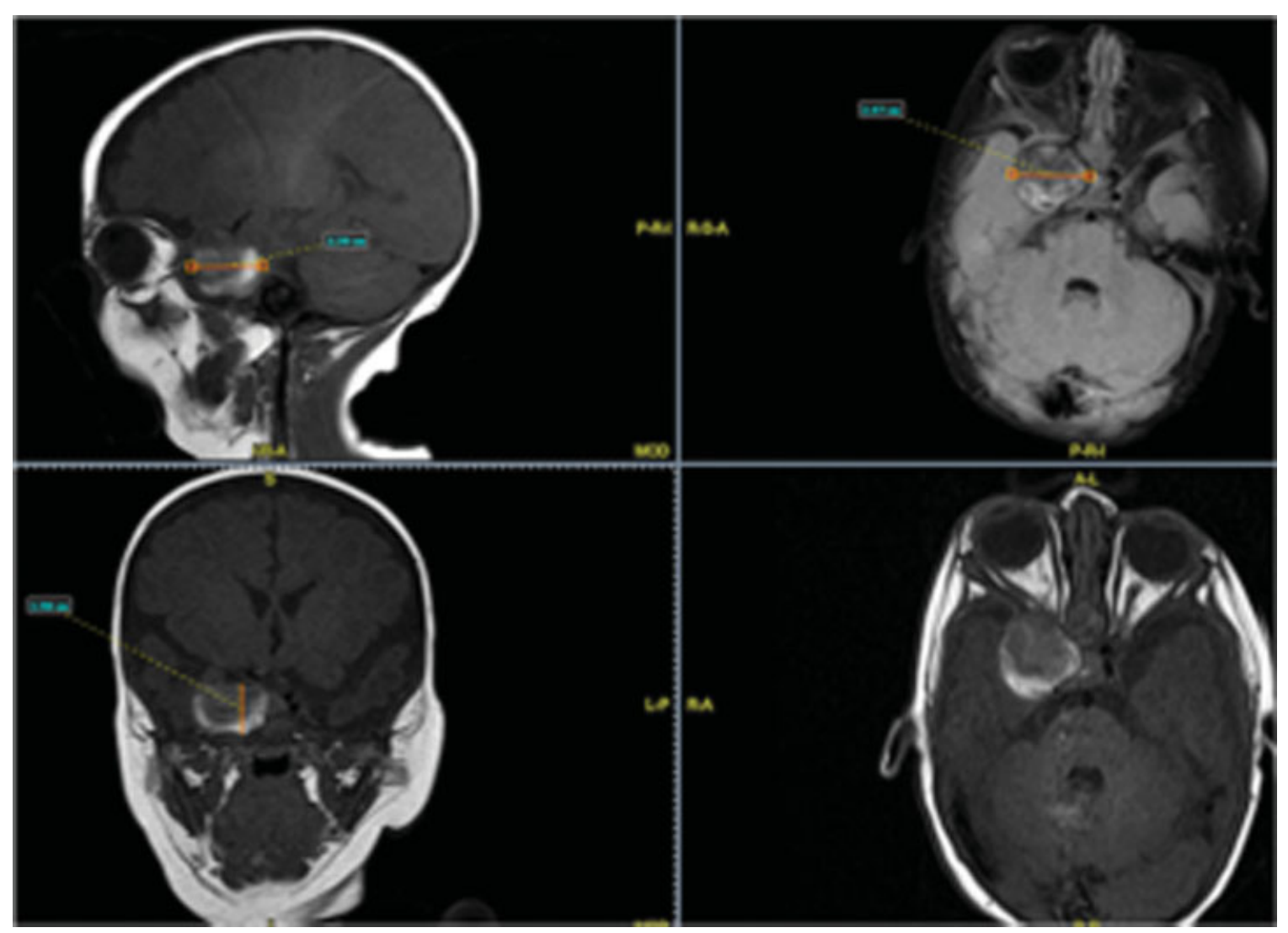

Fig. 2 Magnetic resonance imaging of the brain showing a large retro-orbital mass (giant partially thrombosed aneurysm with $29 \mathrm{~mm}$ ). 

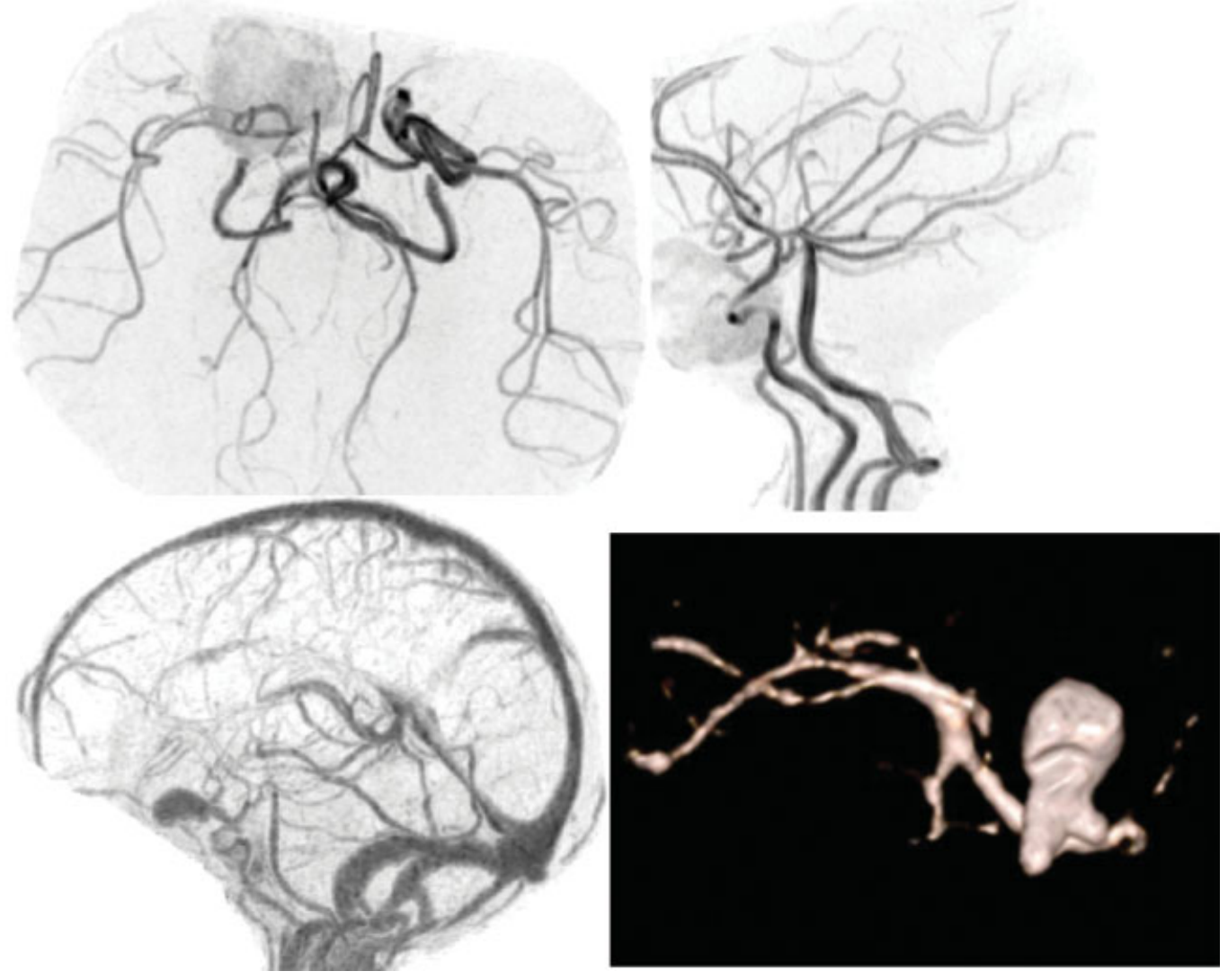

Fig. 3 Computed tomography angiography showing a large, partially thrombosed, aneurysm in the right internal carotid artery. $(A=$ frontal view; $B=$ early arterial phase profile; $C=$ venous phase profile with stagnant aneurysm; $D=3 D$ reconstruction of the patent aneurysm).

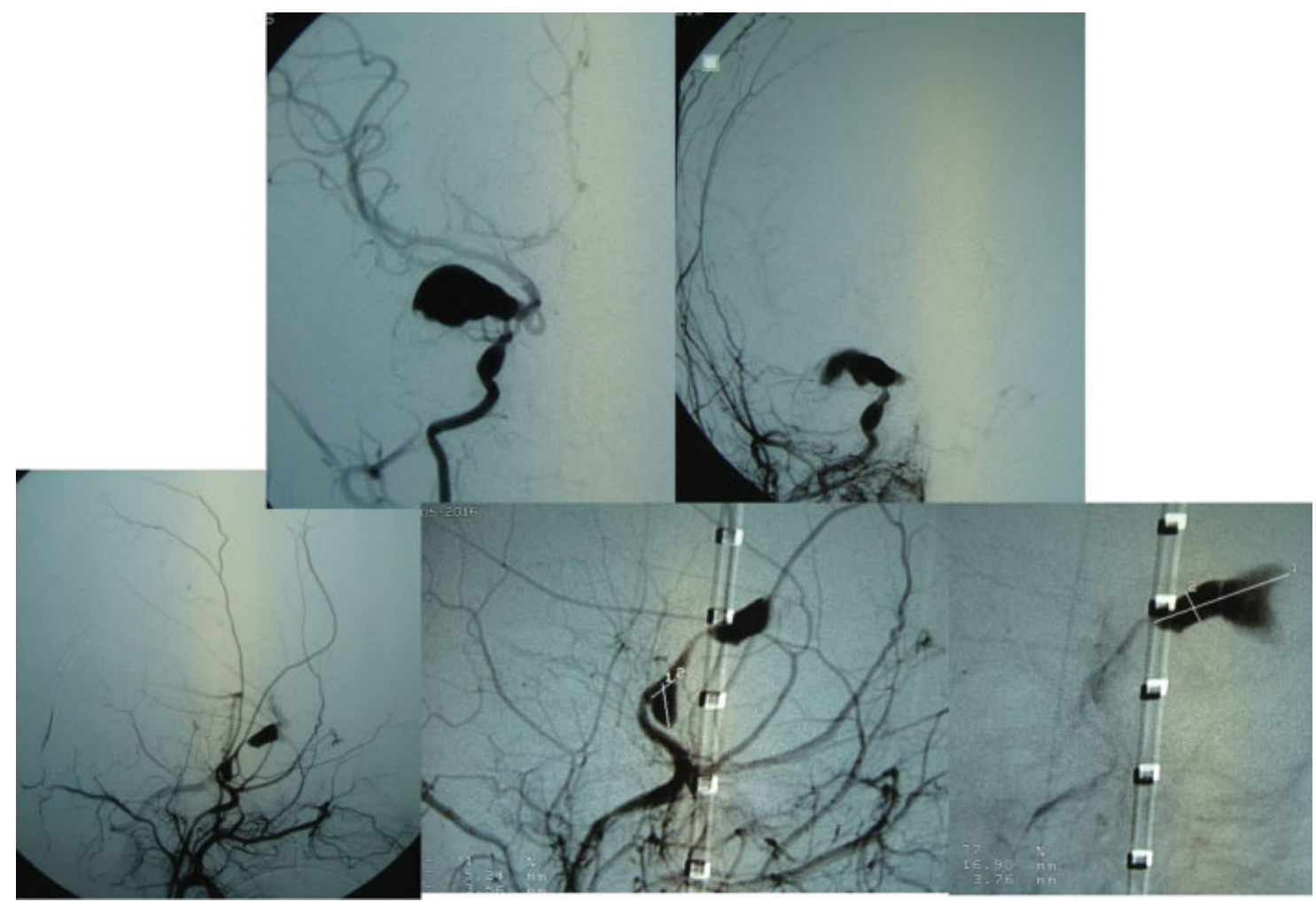

Fig. 4 Digital subtraction angiography of the right internal carotid artery. A and B = frontal view with poor perfusion of the ipsilateral hemisphere; $C$, $D$ and $\mathrm{E}=$ profile view showing two dissecting aneurysms in tandem. The smaller aneurysm was in the supraclinoid region and it measured $5 \mathrm{~mm}$ in the largest diameter, and the larger one was in the ophthalmic segment and it measured $17 \mathrm{~mm}$ in the largest diameter, both with a large neck. 


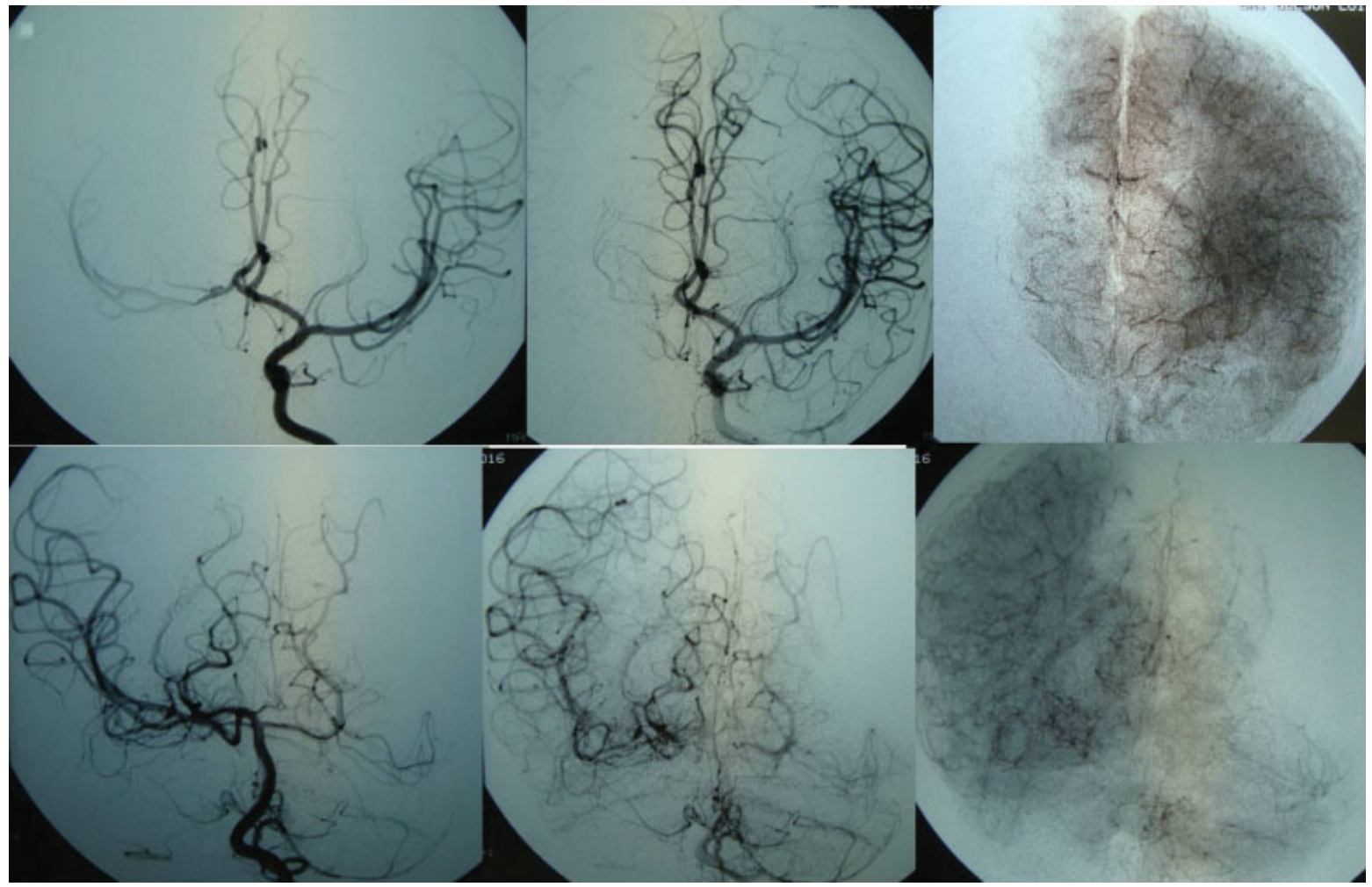

Fig. 5 Matas test with efficient collaterals via contralateral internal carotid artery and a good posterior circulation.

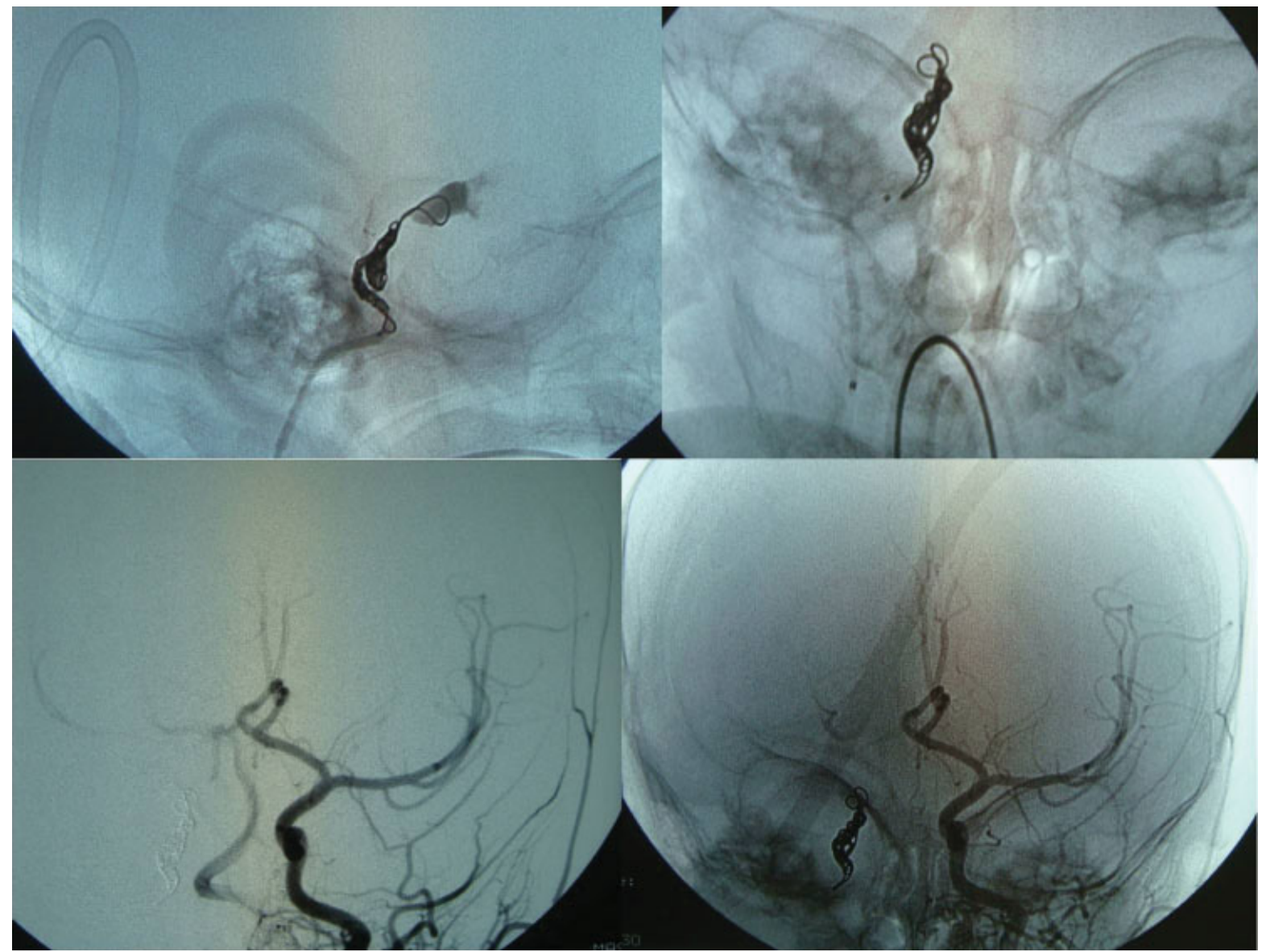

Fig. 6 Occlusion of the internal carotid artery by coils and exclusion of both aneurysms. 


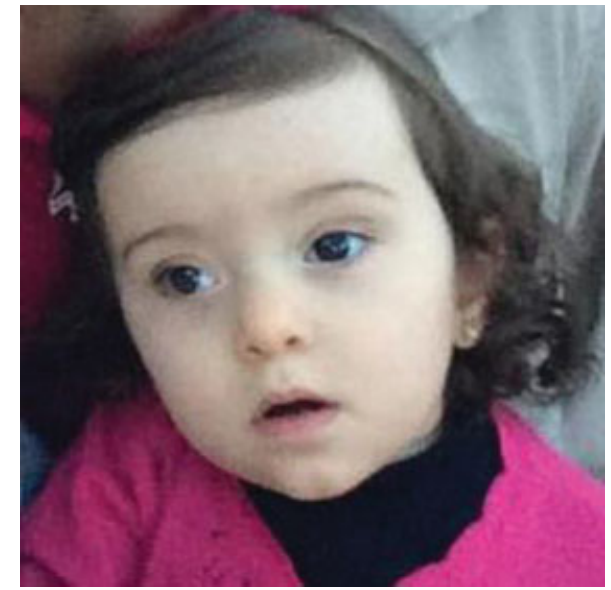

Fig. 7 Improvement of proptosis and ptosis 15 months after the procedure. Image usage authorized by signed and acknowledge Informed Consent.

tuberous sclerosis, sickle cell disease, hereditary hemorrhagic telangiectasia (Osler-Weber-Rendu disease), Klippel-Trenaunay-Weber syndrome, and $\alpha$-1-antitrypsin deficiency. ${ }^{2}$

Aneurysm cases such as the one reported in the present study are usually discussed in a multidisciplinary meeting between neurosurgeons and interventional neuroradiologists at our center.

Surgical clipping is the preferred treatment for most pediatric aneurysms due to the low risk of recurrence over a long-term follow-up, since children have a relatively long life expectancy during which they are at risk of aneurysm rupture. $^{3}$ Whereas giant aneurysms may present proliferative disease in the vessel wall, trapping with proximal and distal parent vessel clipping followed by surgical excision is considered the best therapy, ${ }^{5}$ and could have been an option in this case. ${ }^{3}$ On the other hand, there is no described minimum age to undergo an endovascular treatment, thus this modality may be preferred in early childhood, considering the intricate physiologic requirements and limited blood volume. $^{3}$ Besides, cerebral revascularization may be technically difficult in young children with small arteries.

There are several endovascular options, including artery sacrifice, embolization with single coils, assisted by balloon or stent, and artery wall reconstruction with flow diverters. ${ }^{3}$
However, both stenting and flow diverters require the use of antiplatelet agents for a long period of time, with the risk of the side effects associated with those drugs. ${ }^{3}$ Therapeutic artery occlusion is a quite common treatment option in pediatric aneurysm patients, with numbers as high as $64.7 \%$ for parent artery sacrifice ${ }^{4}$ and $11.8 \%$ for proximal artery occlusion with flow reversal in the artery carrying the aneurysm. ${ }^{4}$ This treatment option was chosen in $16 \%$ of 18 reported cases. ${ }^{2}$ The tolerance to therapeutic vessel occlusion is reported to be better in children than in adults. ${ }^{2}$

\section{Conclusions}

Giant artery aneurysms of the anterior circulation are very rare in infants and a potentially devastating condition. A detailed angiographic investigation is important. In the present case, endovascular intervention was the treatment of choice, although there may be a role for surgery.

Although results are improving with new materials and technical evolution in interventional neuroradiology, a longterm follow-up with surveillance and serial imaging of the embolized aneurysms in childhood is indispensable to prevent recurrence and rebleeding.

\section{Conflicts of Interest}

The authors have no conflict of interests to declare.

\section{References}

1 Lv X, Jiang C, Li Y, Yang X, Wu Z. Endovascular treatment for pediatric intracranial aneurysms. Neuroradiology 2009;51(11):749-754

2 Sorteberg A, Dahlberg D. Intracranial Non-traumatic Aneurysms in Children and Adolescents. Curr Pediatr Rev 2013;9(04):343-352

3 Demartini Z Jr, Matos LAD, Dos Santos MLT, Cardoso-Demartini AdeA. Endovascular Therapeutic Occlusion of the Posterior Cerebral Artery: An Option for Ruptured Giant Aneurysm in a Child. Pediatr Neurosurg 2016;51(04):199-203. Doi: 10.1159/000444193

4 Lasjaunias P, Wuppalapati S, Alvarez H, Rodesch G, Ozanne A. Intracranial aneurysms in children aged under 15 years: review of 59 consecutive children with 75 aneurysms. Childs Nerv Syst 2005;21(06):437-450

5 Fathi NQ, Syahrilfazli AJ, Azizi AB, Redzuan IM, Sobri M, Kumar R. Ruptured giant left distal anterior cerebral artery aneurysm in a two-month-old baby. Pediatr Neurosurg 2015;50(05):275-280 